\title{
Ethnicity and acute myocardial infarction: risk profile at presentation, access to hospital management, and outcome in Norway
}

This article was published in the following Dove Press journal:

Vascular Health and Risk Management

24 August 2012

Number of times this article has been viewed

\author{
M Abdelnoor ${ }^{1,2}$ \\ J Eritsland ${ }^{2}$ \\ C Brunborg' \\ $S$ Halvorsen ${ }^{2}$ \\ 'Unit of Biostatistics and \\ Epidemiology, ${ }^{2}$ Department of \\ Cardiology, Oslo University Hospital \\ Ullevaal, Oslo, Norway
}

Background: Previous studies in North America have shown ethnic variation in the presentation of acute myocardial infarction (AMI), and sex and racial differences in the management and outcome of AMI. In the present study, our aim was to investigate the risk profile of AMI for patients with minority background compared with indigenous Norwegians, at hospital presentation, and to investigate racial differences in hospital care and outcomes.

Patients and methods: A dual-design study was adopted: a cross-sectional study to examine ethnic differences of risk prevalence at hospital presentation and a cohort study to estimate access to angiography, percutaneous coronary intervention (PCI), and hospital and long-term mortality. From a study population of 3105 patients with AMI presenting at Oslo University Hospital between January 1, 2006 and December 31, 2007, we identified 147 cases of AMI in patients with minority background and selected a random sample of 588 indigenous Norwegians with AMI as controls. Prognostic and explanatory strategies were used in the analysis.

Results: Compared with indigenous Norwegians with AMI, AMI patients with minority background suffered their AMI 10 years younger, were generally male, were twice as likely to be smokers, three times as likely to have type 2 diabetes, had lower high-density lipoprotein levels. This group also had 50\% less history of hypertension. In terms of hospital care, AMI patients with minority background had shorter times from onset of symptoms to PCI and the same frequency of access to angiography and acute PCI as indigenous Norwegians when adjusting for the confounding effect of age, sex, and nature of myocardial infarction with or without ST elevation.

Conclusion: At presentation to hospital, patients with minority background had a higher risk profile and a shorter time from onset of symptoms to admission to catheterization laboratory than indigenous Norwegians, but the same access to angiography and acute PCI during hospitalization.

Keywords: ethnicity, myocardial infarction, presentation, management, outcome

\section{Background}

In the USA, extensive research has been done among multiethnic groups that showed significant variations in the presentation of acute myocardial infarction (AMI) among different ethnic groups. In those studies of North American populations, differences between Caucasian, Hispanic and black people were pinpointed. Mehta et $\mathrm{al}^{1}$ found differences in clinical risk factors between African Americans and whites with STelevation myocardial infarction (STEMI) such as hypertension, diabetes, smoking habits, elevated cholesterol, and increased systolic and diastolic blood pressure. Further, Watson et $\mathrm{al}^{2}$ pinpointed that race and sex influence the use of invasive procedure (percutaneous coronary intervention [PCI]) during hospitalization for AMI.
Correspondence: Michael Abdelnoor Centre of Clinical Research, Unit of Epidemiology and Biostatistics, Oslo University Hospital Ullevaal, 0407 Oslo, Norway Tel +4799540888

Fax +4722 II 8479

Email michelab@online.no 
However, there has been limited research among these ethnic populations in Norway. In 1979, a cardiovascular study in Finnmark county reported a discrepancy between risk-factor level and myocardial infarction (MI) incidence among Lapps, Finns, and indigenous Norwegians. ${ }^{3}$ There was also a study pinpointing heterogeneity in cardiovascular risk factors for immigrants in Norway. ${ }^{4}$ Recently, a study outlined the ethnic differences in Systematic COronary Risk Evaluation cardiovascular risk between people with minority background and indigenous Norwegians. ${ }^{5}$

As far as the authors of the present study are aware, as yet, there has been no study comparing ethnic variation in AMI presentation between patients with minority (Middle and Far Eastern) background and indigenous Norwegians. Immigration to Norway from developing countries began about 35 years ago, and $5.5 \%$ of the Norwegian population comprises immigrants from Africa; South and Central America; and Asia, including Turkey. ${ }^{6}$

The aim of this study was to determine whether there was any ethnic discrepancy in prevalence of risk factors in a population hospitalized with AMI in the period 2006 to 2007 in southeastern Norway, between patients with minority background and indigenous Norwegians. The aim was also to assess the difference in hospital access to angiography, acute PCI, and time from onset of symptoms to PCI and hospital and long-term mortality after discharge from hospital.

\section{Patients and methods}

The study population was from Oslo University Hospital Ullevaal, which is the primary medical center for a population of 190,000. It also serves as a secondary cardiac center, performing coronary angiography and PCI for a population of about 1,400,000 in southeastern Norway. The hospital has a 24-hour, 7-days-per-week service for primary PCI. The study population was a cohort of all cases of AMI hospitalized alive at our hospital from January 1, 2006, to December 31, 2007. The cohort comprised 3105 patients.

The registration of patient data started at time of diagnosis. The physician responsible recorded predefined data on patient characteristics, time interval, invasive procedure, medication, and outcome during the hospital stay. Later, data quality was investigated by SH to ensure the quality of the database. To ensure that all patients with AMIs were included, a cross-check against the hospital discharge register was performed, and additional patients not originally identified were included if the diagnosis was considered valid. For patients with multiple hospital admissions during the study period, only the first admission was considered.
The data were entered in an especially designed database developed by the Mid Norway Regional Health Authority (MRS Norsk Hjerteinfarktregister). The closing date of the study for survival analysis was June 30, 2008.

Diagnosis of AMI was based on international criteria ${ }^{7}$ : AMI cases were differentiated as STEMI or non-STEMI based on the initial electrocardiography (ECG) pattern. AMI cases were categorized as STEMI when new ST-elevation or a new left bundle of branch block was present on the index ECG. AMI cases were categorized as non-STEMI if the ECG was normal or showed ST-depression or T-inversion.

The random controls in the comparative cross-sectional design represent the random non-exposed of the cohort study. The procedure was to take away the 147 patients with minority background from the total cohort of 3105 patients. A simple random sample of the remainder of the patients (2958 not with minority background) was generated in Stata (v 11.0; Statacorp, College Station, TX) with a sampling fraction of $19.88 \%$.

The variables considered in this study were defined in the protocol of the register. Hypertension was defined as patients treated for hypertension, and diabetes mellitus was defined as patients treated for diabetes with insulin. Smokers were considered those who currently smoked at the date of AMI. Further, hyperlipidemia was defined as patients under treatment with cholesterol-lowering drugs. The outcome hospital mortality was defined as mortality during the 4 weeks following AMI. Most patients with STEMI admitted to Oslo University Hospital Ullevaal underwent in-hospital coronary angiography. Coronary angiography in STEMI patients was followed by in-hospital PCI. In non-STEMI patients, the frequency of coronary angiography and PCI was considerable lower.

\section{Epidemiological design and statistical methods}

From this population, a comparative cross-sectional study was generated. A flow chart showing the selection of cases and controls is summarized in Figure 1. A total of 147 patients had minority background, as indicated by their name and their origin (Middle or Far East origin, and South American). The distribution of the patients with minority background was as follows: 61 Pakistanis, 28 Turks, 19 Moroccans, and 13 Vietnamese. The remainder had minority background from scattered countries of the Far and Middle East. Non-Norwegian patients of European and other origins were not considered in this study.

As mentioned, this study had a dual design. The comparative cross-sectional study was analyzed using pragmatic 


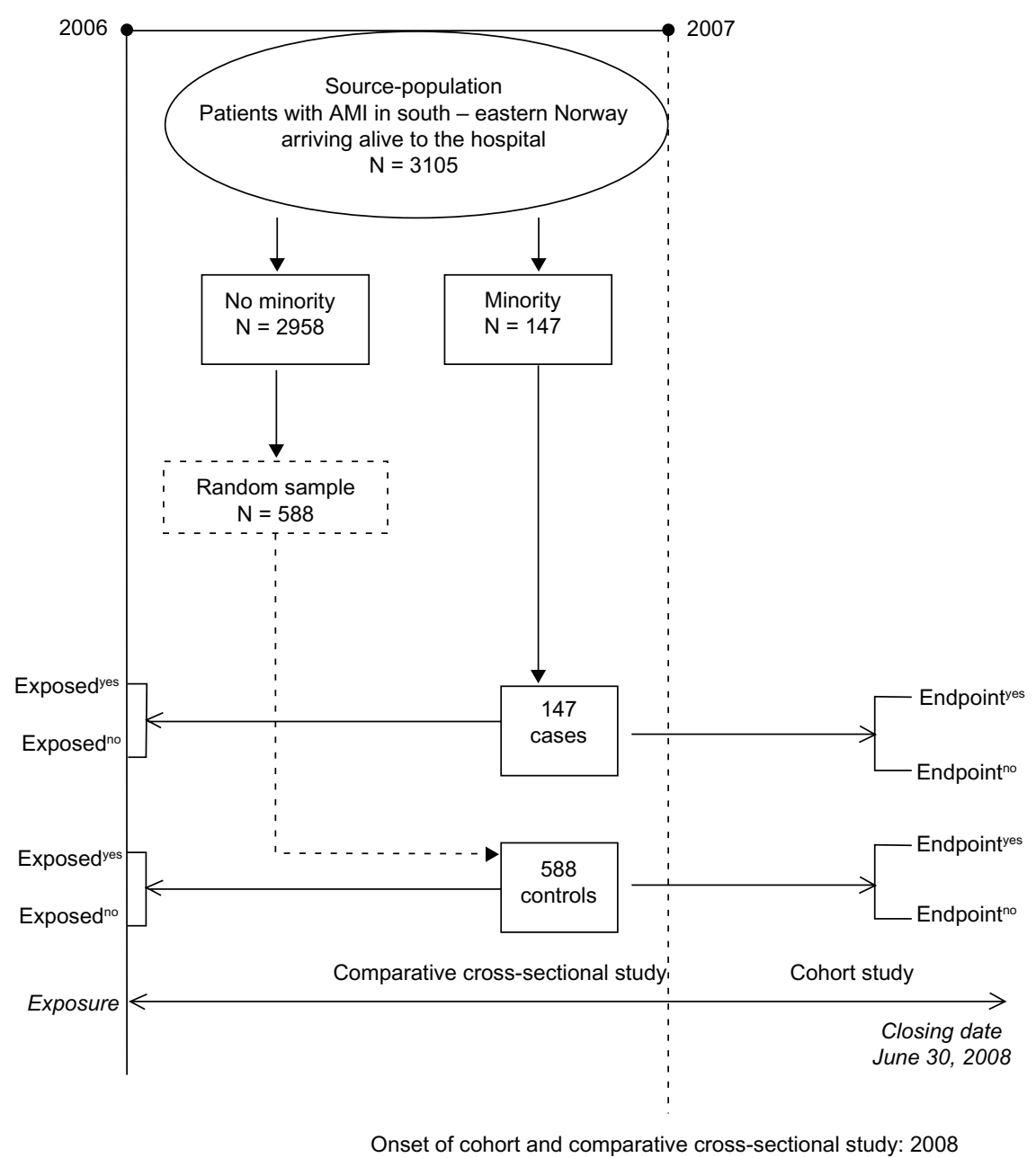

Figure I Flow chart of the dual-design study, incorporating comparative cross-sectional study and cohort study.

strategy, ${ }^{8}$ meaning that priority was not given to a specific hypothesis. Adjacent to this design, exposed (cases) and nonexposed (controls) in a cohort design with outcome hospital and long-term mortality; hospital frequency of angiography, PCI, and aortocoronary bypass graft (ACBG); and time from onset of symptoms to PCI studied. The choice of the controls depends on the research hypothesis; in our study, we were interested in whether patients with specific ethnicities had a different prevalence of AMI risk factors compared with indigenous Norwegians. Thus, if our research hypothesis was to pinpoint risk factors of AMI in patients of specific ethnicity, the controls needed to be a random sample of patients free of AMI from the same source population, ethnicity, and period. Analysis of the cross-sectional design was performed univariately using the contingency tables. The association between potential risk factors and ethnicity was quantified by the odds ratio and its $95 \%$ confidence interval. Age of the patients was polytomized according to the $25 \%, 50 \%$, and $75 \%$ percentiles. The association and gradient effect of the frequency of the major predictors along the four age groups was estimated using the Mantel-Haenszel test of linear trend. ${ }^{9}$ A multivariate analysis using the logistic regression model was performed to pinpoint independent predictors of patients with minority background and AMI in a pragmatic strategy using a manual backward elimination procedure. Multivariate analyses were preceded by estimation of correlations between variables.

As we used a prognostic strategy in the comparative cross-sectional analysis, the predictive accuracy of the model was evaluated by calibration and discrimination. Calibration, which measures the ability of the model to assign the appropriate risk, was evaluated by the HosmerLemeshow (H-L) goodness-of-fit test. The H-L chi square measures the difference between expected and observed outcomes over deciles of risk. A statistically nonsignificant H-L result ( $P$ value $>0.05)$ suggests that, on average, the model predicts accurately. Discrimination, which measured the model's ability to differentiate between those who 
are and are not with minority background, was evaluated by the analysis of the area under the receiver operating characteristic curve (AUC). If the area under the curve is $>0.7$, it can be concluded that the model has an acceptable discriminatory capability.

For the cohort study we had one major endpoint, which was access to PCI during hospital stay. Secondary end points were: access to hospital angiography, access to hospital ACBG, time from onset of symptoms to PCI, early mortality (defined as within 4 weeks following hospitalization), and mortality at a median follow-up time of 500 days after discharge from the hospital. The association between presence of ethnicity and early mortality and access to PCI and to ACBG was quantified using OR and its 95\% CI. As our strategy was explanatory, a stratification analysis was done using the Mantel-Haenszel method to pinpoint effect modifiers and quantify confounders and then controlling for multi-confounders using the logistic regression model. ${ }^{10}$ In terms of the secondary endpoints, time from onset of symptoms to PCI, the control for multi-confounders was done using the multivariate linear regression model. With regard to follow-up time, data was censored with a closing date of June 30, 2008. Patients who died were considered responders at their death date and those who survived after the closing date were considered censored. Kaplan-Meier survival curves were used to determine difference in survival between those with minority background and indigenous Norwegians, and the difference was estimated by the logrank test. ${ }^{11}$ Control for multi-confounders was done using Cox's proportional hazard model with interaction evaluation, when necessary, and Schoenfeld's test was used to investigate the adequacy of the model. ${ }^{11}$ The variables with more than $20 \%$ of the data missing were not considered in the study, as it was difficult to confirm whether they were missing completely at random.

\section{Power estimate for the comparative cross-sectional study}

The power estimate for the comparative cross-sectional study was done beforehand, using current smoking habits. In Norway, the prevalence of smoking is around $30 \%$ of the total population. ${ }^{12}$ Our hypothesis was that this prevalence would vary between $42 \%$ and $53 \%{ }^{5}$ in the population with minority background. Considering four controls per case, an $\mathrm{OR}=1.73$ indicated a hypothetical prevalence of smoking of $42.6 \%$ in cases. Considering a type 1 error of $5 \%$ and a power of $80 \%$, we would need around 140 cases and 558 controls, a total of 698 patients.

\section{Power estimate for the cohort study}

The major end point for the cohort study was access to PCI during hospital stay. A previous study ${ }^{13}$ determined the incidence of PCI to be around $61 \%$ in a population of 3105 AMI patients treated in January 2006 to December 2007 that included both STEMI and non-STEMI. Some investigators ${ }^{14}$ have found that black and Hispanic Americans with AMI have less access to PCI than Caucasian Americans, 32\% versus $40 \%$ - relative risk $(\mathrm{RR})=0.80$, when controlling for major confounders. Further, Casale et $\mathrm{al}^{15}$ showed that the relative risk for African Americans of not undergoing primary PCI, as compared with Caucasians, was 0.78 (95\% CI: 0.67-0.90), after adjusting for confounders. Taking the mean of the results of these two studies $[\mathrm{RR}=(0.80+0.78) / 2=0.79]$, we hypothesized that patients with minority background could have $21 \%$ less access to PCI than indigenous Norwegians. Considering a type 1 error of $5 \%$ and a power of $80 \%$, it was determined that 156 exposed and 644 nonexposed patients would be required - a total of 780 patients.

The Strengthening the Reporting of Observational Studies in Epidemiology recommendations were followed in reporting our study. ${ }^{16}$

\section{Results}

As mentioned, Figure 1 shows as a flow chart the selection of cases and controls. Table 1 summarizes the clinical profiles of AMI patients with minority background versus others. Patients with minority background had three times more type 2 diabetes mellitus, were twice as frequently current smokers, and had 50\% less history of hypertension than the control group. In addition, patients in the case group were twice as likely to be male than those in the control group. In terms of continuous variables, cases were 10 years younger than the controls at the onset of AMI (55 versus 66 years of median age) and had a lower median concentration of HDL (0.99 versus $1.18 \mathrm{mmol} / \mathrm{L})$. Figure 2 shows the regression line between HDL concentration and age with increasing concentration of HDL and advancing age. Our results showing the association between age groups and the different risk factors are summarized in Table 2. With increasing age, there was a decreasing frequency of patients with minority background, decreasing frequency of current smokers, and decreasing frequency of male sex. All these associations showed a gradient effect, as the Mantel-Haenszel test of linear trend was highly significant. There was a weak association between presence of history of hypertension and increasing age but not with frequency of type 2 diabetes mellitus. 
Table I Clinical profile of patients with acute myocardial infarction (MI) of minority versus nonminority background

\begin{tabular}{|c|c|c|c|c|c|}
\hline & $\begin{array}{l}\text { Minority background } \\
n=147(\%)\end{array}$ & $\begin{array}{l}\text { Nonminority background } \\
n=588(\%)\end{array}$ & Odds ratio & $95 \% \mathrm{Cl}$ & P value ${ }^{a}$ \\
\hline Current smokers & $76(51.7)$ & $207(35.2)$ & 1.98 & $1.38-2.87$ & 0.0002 \\
\hline Type 2 diabetes mellitus & $40(27.2)$ & $72(12.2)$ & 2.67 & $1.68-4.23$ & 0.0001 \\
\hline Male sex & $126(85.7)$ & $416(70.7)$ & 2.48 & $1.49-4.28$ & 0.0002 \\
\hline Hyperlipidemia & $13(8.8)$ & $65(11.0)$ & 0.78 & $0.38-1.48$ & 0.4630 \\
\hline History of hypertension & $40(27.2)$ & $236(40.1)$ & 0.56 & $0.36-0.84$ & 0.0038 \\
\hline Previous MI & $25(17.0)$ & $127(21.6)$ & 0.74 & $0.44-1.21$ & 0.2189 \\
\hline Previous stroke & II (7.5) & $54(9.2)$ & 0.80 & $0.37-1.60$ & 0.5160 \\
\hline Previous $\mathrm{PCl}$ & $20(13.6)$ & $73(12.4)$ & 1.11 & $0.62-1.92$ & 0.6978 \\
\hline Previous ACBG & $7(4.8)$ & $34(5.8)$ & 0.81 & $0.30-1.92$ & 0.6297 \\
\hline Presence of STEMI & $85(57.8)$ & $300(51.0)$ & 1.32 & $0.90-1.93$ & 0.1396 \\
\hline \multicolumn{3}{|c|}{ Minority } & Nonminority & & $P$ value ${ }^{b}$ \\
\hline & \multicolumn{2}{|c|}{ Median (Q I-Q3)c } & Median (QI-Q3) & & \\
\hline Age at Ml (years) ${ }^{d}$ & \multicolumn{2}{|c|}{$55.0(47.0-62.0)$} & $66.0(56.0-77.0)$ & & $<0.00001$ \\
\hline Cholesterol (mmol/L) & \multicolumn{2}{|c|}{$5.0(4.3-5.9)$} & $4.9(4.1-5.6)$ & & 0.2767 \\
\hline Creatinine $(\mu \mathrm{mol} / \mathrm{L})$ & \multicolumn{2}{|c|}{$75.0(63.0-91.0)$} & $78(66-93)$ & & 0.1857 \\
\hline $\mathrm{HDL}(\mathrm{mmol} / \mathrm{L})$ & \multicolumn{2}{|c|}{$0.99(0.88-1.15)$} & $1.18(0.97-1.42)$ & & $<0.0000 \mathrm{I}$ \\
\hline Maximum treponin $(\mu \mathrm{mol} / \mathrm{L})$ & \multicolumn{2}{|c|}{$2.13(0.77-5.86)$} & I.67 (0.52-5.47) & & 0.2133 \\
\hline
\end{tabular}

Notes: aChi-square test; bMann-Whitney $\mathrm{U}$ test; ${ }^{\mathrm{C}} \mathrm{Q}$ I: $25 \%$ quartile, Q3: $75 \%$ quartile. ${ }^{\mathrm{d}}$ Excluding patients with previous $\mathrm{MI}(\mathrm{n}=\mathrm{I} 2 \mathrm{2})$, the difference in median age between patients from a minority background and those who were indigenous Norwegians was 10 years (54 years vs 64 years), $P=0.00 \mathrm{I}$.

Abbreviations: ACBG, aortocoronary bypass graft; $\mathrm{Cl}$, confidence interval; $\mathrm{HDL}$, high-density lipoprotein; PCl, percutaneous coronary intervention; STEMI, ST-segment elevation myocardial infarction.

A final analysis was done to highlight the independent predictors for ethnicity for AMI patients using the manual backward elimination procedure and the logistic regression model. Due to the association between age and concentration of HDL, age and current smoker status, male sex and history of hypertension, two multivariate models, shown in Table 3, were needed to avoid multicollinearity problems. Model A shows that, compared with patients with AMI and Norwegian background, patients with AMI and minority background had twice the prevalence of smoking, three times more type 2 dia-

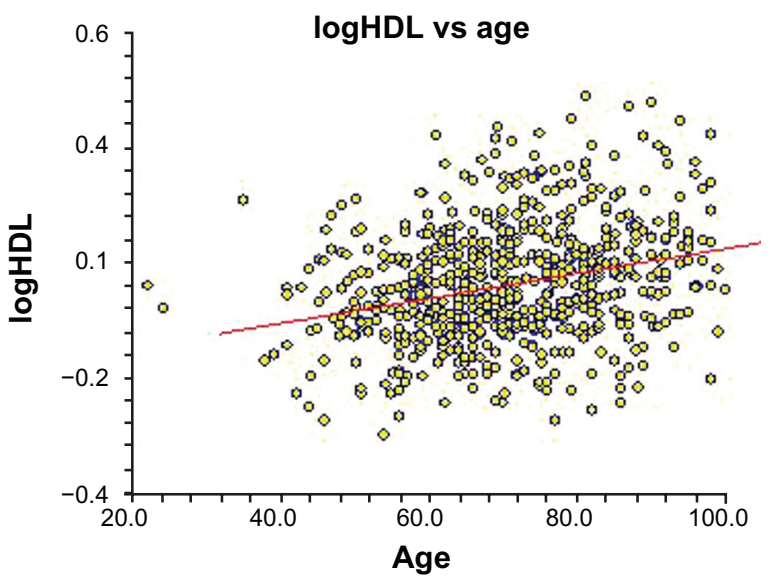

Figure 2 Regression line showing the association between concentration of serum high-density lipoprotein (HDL) and age. betes mellitus, and two times more HDL $<0.9 \mathrm{mmol} / \mathrm{L}$. Further, this group included twice as many males than the other. However, patients with AMI and minority background were 10 years younger at onset of their AMI and had $50 \%$ less history of hypertension. Model B informs us that patients with AMI and minority background had three times more type 2 diabetes mellitus and were 3.5 times more likely to be younger than 54 years old than indigenous Norwegian patients with AMI.

As a prognostic strategy was used, the calibration and discrimination of the model were important issues. The calibration was assessed by plotting the observed proportion of events against the predicted probabilities by groups defined by predicted risks. Goodness of fit was tested with the H-L test for Model A with five risk factors (chi square $=13.8$, number of groups $=10, P$ value $=0.1810$ ). For Model $\mathrm{B}$ with two risk factors, chi-square was 14.52 , the number of groups was 10 , and the $P$ value was 0.1506 . The H-L test was not significant, indicating a useful goodness of fit for the two models and that they would predict satisfactorily, both on average and across ranges of patients and deciles of risk. Thus, the models were deemed suitable for use in all (low- to high-risk) patients. Additionally, the two predictors of ethnicity models constructed demonstrated an acceptable discriminatory power. The AUC was 0.7036 (95\% CI: 0.669-0.736) for Model A and 0.762 (95\% CI: 0.729-0.792) for Model B. 
Table 2 Gradient effect of age interval by quartiles and frequency of risk factors using the Mantel-Haenszel test of linear trend

\begin{tabular}{|c|c|c|c|c|c|}
\hline & \multicolumn{5}{|c|}{ Age (years) } \\
\hline & $\leq \mathbf{5 4 . 0}$ & $54.0-61.9$ & $62.0-74.9$ & $\geq 75.0$ & Tota \\
\hline \multicolumn{6}{|l|}{ Minority } \\
\hline Yes & 62 & 48 & 28 & 9 & 147 \\
\hline No & 112 & 126 & 172 & 178 & 588 \\
\hline Total & 174 & 174 & 200 & 187 & 735 \\
\hline Frequency (\%) & 35.6 & 27.5 & 14.0 & 4.8 & 20.0 \\
\hline $\mathrm{OR}^{\mathrm{a}}(95 \% \mathrm{Cl})$ & 1.00 & $0.69(0.43-I . I I)$ & $0.29(0.17-0.50)$ & $0.09(0.04-0.20)$ & \\
\hline \multicolumn{6}{|l|}{ Current smoker } \\
\hline Yes & 115 & 85 & 59 & 24 & 283 \\
\hline No & 59 & 89 & $14 \mid$ & 163 & 452 \\
\hline Total & 174 & 174 & 200 & 187 & 735 \\
\hline Frequency (\%) & 66.1 & 48.8 & 29.5 & 12.8 & 38.5 \\
\hline $\mathrm{OR}^{\mathrm{b}}(95 \% \mathrm{Cl})$ & 1.0 & $0.49(0.3 \mathrm{I}-0.77)$ & $0.21(0.14-0.34)$ & $0.08(0.04-0.13)$ & \\
\hline \multicolumn{6}{|l|}{ Male sex } \\
\hline Yes & 150 & 146 & 145 & 101 & 542 \\
\hline No & 24 & 28 & 55 & 86 & 193 \\
\hline Total & 174 & 174 & 200 & 187 & 735 \\
\hline Frequency (\%) & 86.0 & 83.0 & 72.5 & 54.0 & 73.7 \\
\hline $\mathrm{OR}^{\mathrm{c}}(95 \% \mathrm{Cl})$ & 1.00 & $0.83(0.44-1.57)$ & $0.42(0.24-0.74)$ & $0.19(0.11-0.32)$ & \\
\hline \multicolumn{6}{|c|}{ History of hypertension } \\
\hline Yes & 34 & 65 & 89 & 88 & 276 \\
\hline No & 146 & 109 & 111 & 99 & 459 \\
\hline Total & 174 & 174 & 200 & 187 & 735 \\
\hline Frequency (\%) & 19.5 & 37.1 & 44.5 & 47.0 & 37.6 \\
\hline $\mathrm{OR}^{\mathrm{d}}(95 \% \mathrm{Cl})$ & 1.00 & $2.56(1.54-4.28)$ & $3.44(2.11-5.64)$ & $3.82(2.32-6.29)$ & \\
\hline \multicolumn{6}{|c|}{ Type 2 diabetes mellitus } \\
\hline Yes & 19 & 25 & 41 & 27 & 112 \\
\hline No & 155 & 149 & 159 & 160 & 623 \\
\hline Total & 174 & 174 & 200 & 187 & 735 \\
\hline Frequency (\%) & 10.9 & 14.3 & 20.5 & 14.4 & 15.2 \\
\hline $\mathrm{OR}^{\mathrm{e}}(95 \% \mathrm{Cl})$ & 1.00 & $1.37(0.69-2.7 I)$ & $2.10(1.13-3.95)$ & $1.38(0.70-2.70)$ & \\
\hline
\end{tabular}

Notes: ${ }^{a}$ Chi square of linear trend: $63.608, \mathrm{df}=\mathrm{I}, \mathrm{P}$ value $<0.000 \mathrm{I}$; ${ }^{\mathrm{b}}$ chi square of linear trend: I22.4I7, df $=1$, $P$ value $<0.000 \mathrm{I}$; ${ }^{\mathrm{c}}$ chi square of linear trend: $54.734, \mathrm{df}=\mathrm{I}, \mathrm{P}$ value $<0.000 \mathrm{I}$; ${ }^{\mathrm{d}} \mathrm{chi}$ square of linear trend: $33.0 \mathrm{I} 5 \mathrm{df}=\mathrm{I}, \mathrm{P}$ value $<0.000 \mathrm{I}$; ${ }^{\mathrm{e}}$ chi square of linear trend: I.936, $\mathrm{df}=\mathrm{I}, \mathrm{P}$ value $=0.164 \mathrm{I}$. Abbreviations: $\mathrm{Cl}$, confidence interval; df, degrees of freedom; OR, odds ratio.

The analysis of the cohort study, examining outcome hospital mortality; hospital access to angiography, PCI, and ACBG; and 1-year survival, used the explanatory strategy, meaning that investigation of the presence of confounders and effect modifiers for every end point was mandatory.
Table 4 shows that for those with STEMI, early mortality and long-term mortality were lower for patients from the minority background group, while both groups had the same incidence of hospital angiography and hospital access to PCI and ACBG.

Table 3 Risk factors differentiating patients with acute myocardial infarction of minority background versus those from nonminority background using the multivariate logistic model with a prognostic strategy

\begin{tabular}{|c|c|c|c|c|c|}
\hline Predictors & Level & Odds ratio & $\mathbf{9 5} \%$ confidence interval & $\mathbf{Z}$ & $P$ value \\
\hline \multicolumn{6}{|l|}{ Model A } \\
\hline Current smoker & Yes/no & 1.92 & $1.30-2.83$ & 3.30 & 0.001 \\
\hline Type 2 diabetes mellitus & Yes/no & 3.26 & $2.03-5.25$ & 4.87 & $<0.001$ \\
\hline $\mathrm{HDL}$ cholesterol $<0.95 \mathrm{mmol}$ & Yes/no & 2.09 & $1.39-3.15$ & 3.55 & $<0.001$ \\
\hline Male sex & Yes/no & 1.92 & $1.15-3.23$ & 2.48 & 0.013 \\
\hline Treated hypertension & Yes/no & 0.52 & $0.34-0.81$ & -2.93 & 0.003 \\
\hline \multicolumn{6}{|l|}{ Model B } \\
\hline Diabetes mellitus type 2 & Yes/no & 3.21 & $2.02-5.09$ & 4.95 & $<0.001$ \\
\hline Age $<54$ years & Yes/no & 3.54 & $2.39-5.23$ & 6.31 & $<0.001$ \\
\hline
\end{tabular}

Note: Two-model presentation was used to avoid the problem of multicollinearity between the predictors of ethnicity.

Abbreviation: HDL, high-density lipoprotein. 
Table 4 Hospital outcomes and mortality stratified on the nature of acute myocardial infarction ST-segment elevation myocardial infarction (STEMI) versus non-STEMI

\begin{tabular}{|c|c|c|c|}
\hline & Minority background & Nonminority background & $P$ value \\
\hline STEMI ( $\mathbf{N}=385)$ & $\mathrm{n}=\mathbf{8 5}$ & $\mathrm{n}=\mathbf{3 0 0}$ & \\
\hline Hospital mortality & $\mathrm{I}(\mathrm{I} .2 \%)$ & $20(6.6 \%)$ & 0.05 \\
\hline Hospital angiography & $84(99 \%)$ & 287 (96\%) & 0.16 \\
\hline Hospital access to $\mathrm{PCl}$ & $74(87 \%)$ & $24 I(80.3 \%)$ & 0.15 \\
\hline Hospital access to ACBG & $0(0 \%)$ & $2(0.6 \%)$ & 0.60 \\
\hline Mors/patients days ${ }^{\mathrm{a}}$ & $2 / 41777$ & $42 / 146800$ & \\
\hline Mortality rate (deaths per 10,000 ) & 0.4787 & 2.861 & 0.004 \\
\hline \multicolumn{4}{|l|}{ Time delay to primary $\mathrm{PCl}$, minutes $\mathrm{s}^{\mathrm{b}-\mathrm{d}}$} \\
\hline Symptom-to-balloon time & I 77 ( $\mid$ | 7-345) & $255(143-4 \mid 5)$ & 0.003 \\
\hline Door-to-balloon time & $36.5(30-56)$ & $34.0(27-44)$ & 0.06 \\
\hline Non-STEMI (N = 350) & $n=62$ & $\mathrm{n}=\mathbf{2 8 8}$ & \\
\hline Hospital mortality & $\mathrm{I}(\mathrm{I} .6 \mathrm{I} \%)$ & $20(6.9 \%)$ & 0.11 \\
\hline Hospital angiography & $6 I$ (98.3\%) & $225(78.1 \%)$ & 0.0001 \\
\hline Hospital access to $\mathrm{PCl}$ & 26 (4I.9\%) & $107(37.1 \%)$ & 0.48 \\
\hline Hospital access to ACBG & $\mathrm{I}(\mathrm{I} .6 \mathrm{I} \%)$ & $8(2.7 \%)$ & 0.50 \\
\hline Mors/patients days & $4 / 29429$ & $50 / 135237$ & \\
\hline Mortality rate (deaths per 10,000 ) & 1.359 & 3.697 & 0.05 \\
\hline
\end{tabular}

Notes: a Median follow up time $=500$ days; ${ }^{\text {bmedian }}$ with $25 \%$ and $75 \%$ quartile; CMann-Whitney $U$ test; dadjusting for age, sex, and smoking habit using the linear regression model, the differences in time delay to primary $\mathrm{PCl}$ in minutes continued to be significantly different for the minority group compared with the nonminority group $(P$ value $=0.02)$.

Abbreviations: $\mathrm{ACBG}$, aortocoronary bypass graft; $\mathrm{PCl}$, percutaneous coronary intervention.

Additionally, it is interesting to highlight that there was a significant difference between time of onset of symptoms to admission to catheterization laboratory and PCI between patients with minority background and indigenous Norwegians (177 versus 255 minutes median time). It continued to be significant when controlling for the confounding effects of age, sex, and smoking habit. However, there was no difference between time to presentation to hospital and PCI ( 34.0 versus 36.5 minutes) between the two groups.

For non-STEMI patients, there was a difference in hospital access to angiography and a difference in longterm follow-up between the two groups, while hospital mortality, access to PCI and ACBG were the same. Another investigator ${ }^{13}$ has shown that sex and the nature of the AMI (STEMI versus non-STEMI) were important confounders. Controlling for different confounders, as shown in
Table 5, revealed that there was no statistical difference in hospital mortality and access to angiography, PCI, and ACBG. Our study is powered for the outcome incidence of hospital angiography and PCI, but is power deficient for the outcomes incidence of mortality and incidence of ACBG during hospital stay. Thus, as far as these latter two end points are concerned, our results are inconclusive.

With regard to the outcome survival at median follow-up time of 500 days after AMI, the results of the Kaplan-Meier method (Figure 3) showed that patients with minority background had a slightly better survival at 1-year follow-up than indigenous Norwegians $(97.8 \%$ [standard error $=1.22$ ] versus $87.9 \%$ [standard error $=1.37$ ] log-rank test, respectively; $P=0.0007)$. Controlling for the confounder effects of age, sex, and nature of AMI (STEMI versus non-STEMI) highlighted that there was no statistical difference in mortality between the two

Table 5 Adjusted odds ratio (OR) for patients with acute myocardial infarction (AMI) with minority background versus those from nonminority background using a logistic regression model and Cox's regression model, controlling for multi-confounders

\begin{tabular}{|c|c|c|c|c|}
\hline End point & Minority vs nonminority & OR* & $\mathbf{9 5} \%$ confidence interval & $P$ value \\
\hline Hospital mortality ${ }^{\mathrm{a}}$ & Yes/no & 0.45 & $0.10-2.03$ & 0.298 \\
\hline Hospital angiography ${ }^{\mathrm{b}}$ & Yes/no & 3.8 & $0.48-30.1$ & 0.206 \\
\hline Hospital $\mathrm{PCl}^{\mathrm{c}}$ & Yes/no & 0.86 & $0.57-\mid .31$ & 0.499 \\
\hline \multirow[t]{2}{*}{ Hospital ACBG } & Yes/no & 0.43 & $0.05-3.81$ & 0.453 \\
\hline & & $\mathbf{H} \mathbf{R}^{* *}$ & & \\
\hline 500 days follow-up mortalitye & Yes/no & 0.57 & $0.24-1.35$ & 0.205 \\
\hline
\end{tabular}

Notes: *Estimated from the logistic regression model; **estimated from Cox's regression model; adjusting for the confounding effect of age; badjusting for the confounding effect of age, sex, and presence of STEMI versus non-STEMI AMI; ' adjusting for the confounding effect of age, sex, and presence of STEMI versus non-STEMI AMI; 'adjusting for the confounding effect of age and presence of diabetes mellitus; eadjusting for the confounding effect of age, sex, and presence of STEMI versus non-STEMI AMI.

Abbreviations: ACBG, aortocoronary bypass graft; HR, hazard ratio; $\mathrm{PCl}$, percutaneous coronary intervention. 


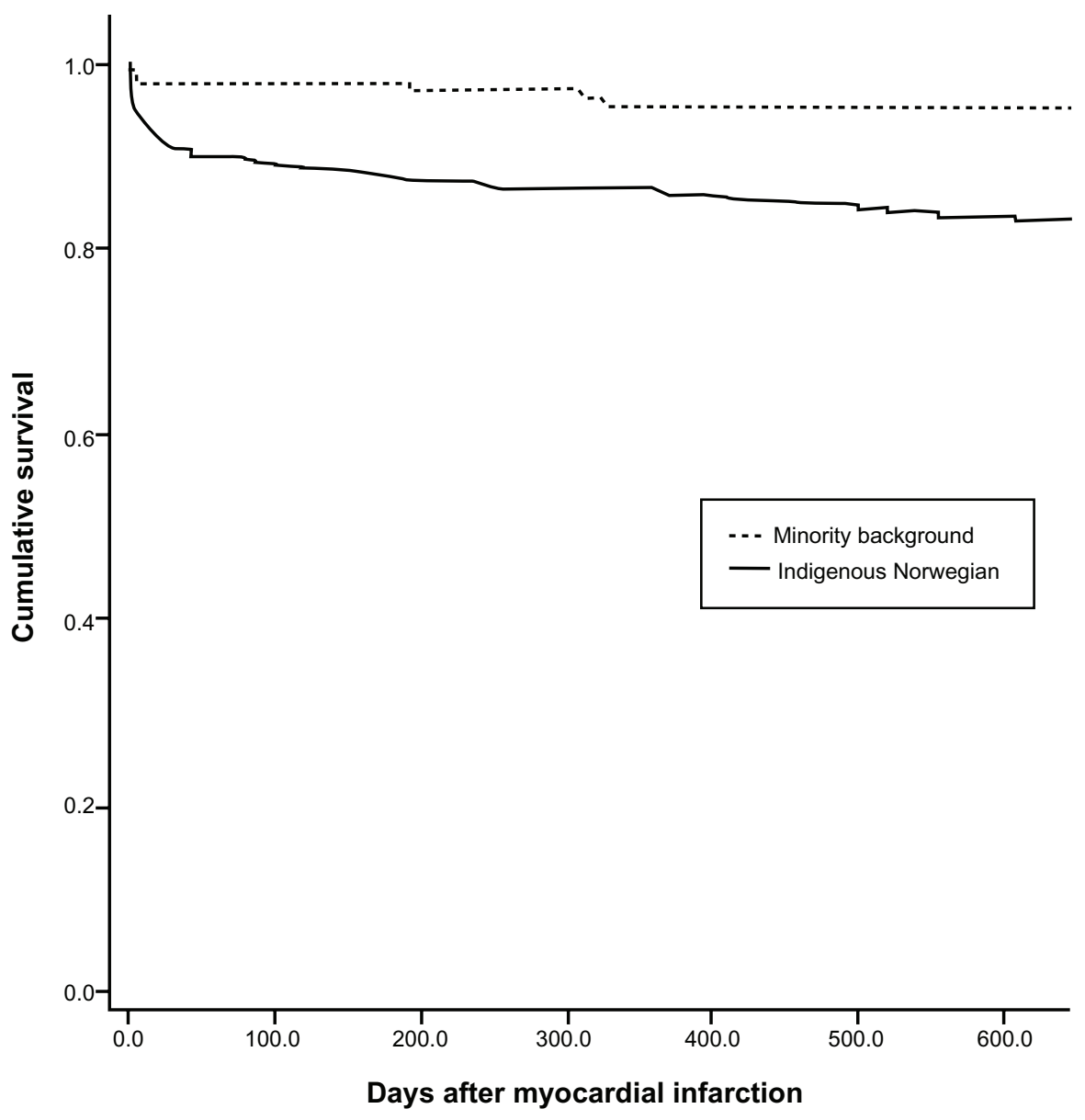

Figure 3 Kaplan-Meier survival plot for patients with minority background versus indigenous Norwegian patients. Note: Median follow-up time was 500 days after acute myocardial infarction (univariate analysis).

groups at a median follow-up time of 500 days. Unfortunately, our study is power deficient for this end point and our results concerning long-term mortality are not conclusive.

\section{Discussion}

In the present study, clinically important ethnic differences were found in the prevalence of established risk factors of AMI. Compared with indigenous Norwegians, patients with minority background had a higher prevalence of smoking, being male, and type 2 diabetes mellitus. Further, patients with minority background had lower HDL cholesterol concentrations, a lower prevalence of hypertension, and were 10 years younger than indigenous Norwegian patients. However, they had the same access to angiography and PCI salvation when controlling for the confounding effects of age, sex, and presence of ST elevation.

In defining case patients with minority background, there is a small probability that some cases were misclassified, as some patients with minority background may have had Norwegian ethnic names. Further, a minor selection bias is possible, as only patients arriving to the emergency department alive with AMI diagnosis were considered in our study. We believe the possibility of information bias, as far exposition to major risk factors is concerned, was minimal. Most information on risk factors was taken from the medical history of the patients and laboratory analyses that were done at admission to hospital and during hospital stay by interviewing the patient. The resident physician was unaware of our research hypothesis and because of that misclassification of these exposures was a non-differential misclassification, ${ }^{9}$ which could have created a bias toward the null effect. Misclassification of the outcomes was unlikely in the cohort. The control for confounders was not complete, as there was possibility of unmeasured confounding bias because reliable markers of obesity and socioeconomic status of the patients were not available. Further, other variables that influence symptom presentation were missing, such as education and health literacy status, which could represent unmeasured confounders. 


\section{Difference in risk prevalence at hospital presentation}

Other investigators ${ }^{5}$ have been interested in this subject but not with reference to a population suffering from AMI. In a cross-sectional design of immigrant versus indigenous Norwegians, Kumar et al found a large difference between the two groups in terms of generalized obesity, defined as body mass index $\geq 30 \mathrm{~kg} / \mathrm{m}^{2}$ and central obesity waist:hip ratio $\geq 0.85 .{ }^{17}$

The Oslo immigrant health profile, conducted in 2002 , was a large population-based cross-sectional study (3726 persons) carried out in Oslo. ${ }^{17}$ Results from that study showed that immigrant groups differed significantly both among themselves and from indigenous Norwegians regarding risk factors. The groups of immigrants in this study were mainly from Vietnam, Sri Lanka, Pakistan, and Turkey. Smoking habits varied across these groups; however, men smoked more than women and all had a higher prevalence of smoking than indigenous Norwegians. There was a prevalence ratio varied from 1.3 for Pakistanis to 2.0 for Turkish, and this result is close to our findings of $\mathrm{OR}=1.9$ between minority background and indigenous Norwegians.

Type 2 diabetes mellitus was sex dependent in the minority background population, being more prevalent in females than males. For males, the prevalence ratio varied from 1.0 for Iranians to 6.0 for Pakistanis and for females from 3.0 for Iranians to 14.0 for Pakistanis.

Lower HDL is an indicator of physical inactivity and levels were lower in our population of minority background AMI patients. This fact has been determined in immigrant studies, in which immigrants were found to have a ratio of prevalence three times higher of physical inactivity than indigenous Norwegians. ${ }^{17}$ This could explain the lower levels of HDL in our population of minority AMI patients.

Another interesting finding is that our AMI cases had a $48 \%$ lower frequency of treated hypertension than the indigenous Norwegians. This result is in concordance with the immigrant study, ${ }^{17}$ which found a $20 \%$ to $50 \%$ lower prevalence in treated hypertension in immigrants compared with indigenous Norwegians. Unfortunately, other important risk factors of atherosclerosis, such as obesity and low socioeconomic status, were not considered in our study and are missing from this comparative profile. Although we were aware of heterogeneity in risk profile among immigrants in Norway, ${ }^{4}$ because of power deficiency, a subgroup analysis comparing different immigrant groups with indigenous Norwegians was not performed.
Numerous investigators in Sweden ${ }^{18-21}$ have reported a higher prevalence of known risk factors for coronary heart disease among immigrants in comparison to indigenous Swedes, including smoking, diabetes, obesity, dyslipidemia, and low physical activity.

Some genetic factors could be responsible for the difference in the frequencies of risk factors of coronary heart disease between different ethnic groups, including immigrants, as suggested by some investigators. ${ }^{22,23}$

\section{Identical management of AMI}

What is interesting to underscore is that AMI patients with minority background had a higher risk profile than indigenous Norwegians, but the same access to hospital angiography and acute PCI. The shorter time from onset of symptoms to PCI was due to the fact that patients with minority background tend to live in larger cities, while indigenous Norwegian are scattered throughout the country. This result of no delay in presentation to hospital was in contradiction with data from Canada $^{24}$ indicating that South Asians were 70\% less likely than Caucasians to report to the emergency department within 3 hours of symptom onset.

Our results contradict studies from North America that report that there is less access to medical care for black and Hispanic patients with AMI compared with Caucasian Americans. This contradiction is presumably due to the nature of social and egalitarian medicine in Norway compared with that of the USA.

A major US study ${ }^{25}$ underlined sex and racial differences in the management of AMI during the period 1994-2002. Mainly, black men and women had less access to angiography in hospital than white men and this $10 \%$ lower access was unchanged over time.

Further, another US study ${ }^{14}$ pinpointed that access to PCI was lower for blacks than whites, $32 \%$ versus $40 \%$. This difference persisted after controlling for major confounders and have been confirmed by Echols et al, ${ }^{26}$ Venkat et al, ${ }^{27}$ and, in Canada, by King et al. ${ }^{24}$ Other authors also found this disparity in different population groups in the USA and it was found to exist regardless of service availablity ${ }^{28}$ Moreover, it continued to exist even when groups had similar levels of health insurance and ability to pay for costly procedures. Considering all these findings, there is no explanation for these racial disparities. ${ }^{29}$

Recently, a statewide study on ethnicity and PCI in the USA during the period 2003-2004 ${ }^{15}$ concluded that in patients with STEMI primary PCI was used less often in African Americans and lower-income patients, independent 
of clinical hospitals and insurance characteristics, identifying persistent disparities in application of cardiac care.

\section{Conclusion}

This study found that AMI patients with minority background (Far- or Middle Eastern) had a higher prevalence of risk profile and were 10 years younger than indigenous Norwegians at time of presentation to hospital, but had the same access to angiography and acute PCI and a shorter time from symptom appearance to admission to catheterization laboratory.

\section{Disclosure}

This study was not funded by an external source. The authors declare no conflicts of interest in this work.

\section{References}

1. Mehta RH, Marks D, Califf RM, et al. Differences in the clinical features and outcomes in African Americans and whites with myocardial infarction. Am J Med. 2006;119(1):70. e1-e8.

2. Watson RE, Stein AD, Dwamena FC, et al; Michigan State University Inter-Institutional Collaborative Heart Study Group. Do race and gender influence the use of invasive procedure? J Gen Intern Med. 2001;16(4):227-234.

3. Thelle DS, Førde OH. The cardiovascular study in Finnmark county: coronary risk factors and the occurrence of myocardial infarction in first degree relatives and in subjects of different ethnic origin. Am J Epidemiol. 1979;110(6):708-715.

4. Glenday K, Kumar BN, Tverdal A, Meyer HE. Cardiovascular disease risk factors among five major ethnic groups in Oslo, Norway: the Oslo Immigrant Health Study. Eur J Cardiovasc Prev Rehabil. 2006;13(3):348-355.

5. Kumar BN, Selmar R, Lindman AS, Tverdal A, Falster K, Meyer HE. Ethnic differences in SCORE cardiovascular risk in Oslo, Norway. Eur J Cardiovasc Prev Rehabil. 2009;16(2):229-234.

6. Statistics Norway. Population [web page on the Internet]. Oslo: Statistics Norway; nd. Available from: http://www.ssb.no/befolkning_en/. Accessed July 10, 2012.

7. Alpert JS, Thygesen K, Antman E, Basand JP. Myocardial infarction redefined - a consensus document of The Joint European Society of Cardiology/American College of Cardiology Committee for the redefinition of myocardial infarction. J Am Coll Cardiol. 2000;36(3):959-969.

8. Abdelnoor M, Sandven I. Etiologisk versus prognostisk strategi i klinisk epidemiologisk forskning [Explanatory versus prognostic strategy in clinical research]. Nor Epidemiol. 2006;16(2):77-80. Norwegian.

9. Kleinbaum DG, Kupper LL, Morgenstern H. Epidemiologic Research: Principles and Quantitative Methods. New York: Van Nostrand Reinhold; 1982.

10. Kleinbaum DG, Klein M. Logistic Regression: A Self-Learning Text. 3rd ed. New York, NY: Springer-Verlag; 2010.

11. Kleinbaum DG, Klein M. Survival Analysis: A Self-Learning Text. 2nd ed. New York, NY: Springer Science+Business Media; 2005.

12. Statistics Norway. Smoking habits 2011: less smoking, more use of snuff [web page on the Internet]. Oslo: Statistics Norway; February 17, 2012. Available from: http://www.ssb.no/english/subjects/03/01/royk_en/. Accessed July 10, 2012.
13. Halvorsen S, Eritsland J, Abdelnoor M, et al. Gender differences in management and outcome of acute myocardial infarctions treated in 2006-2007. Cardiology. 2009;114(2):83-88.

14. Maynard C, Litwin PE, Martin JS, et al. Characteristics of black patients admitted to coronary care units in metropolitan Seattle: results from the Myocardial Infarction Triage and Intervention Registry (MITI). Am J Cardiol. 1991;67(1):18-23.

15. Casale SN, Auster CJ, Wolf F, Pei Y, Devereux RB. Ethnicity and socioeconomic status influence use of primary angioplasty in patients presenting with acute myocardial infarction. Am Heart $J$. 2007;154(5):989-993.

16. von Elm E, Altman DG, Egger M, Pocock SJ, Gøtzsche PC, Vandenbroucke JP; STROBE Initiative. The Strengthening the Reporting of Observational Studies in Epidemiology (STROBE) statement: guidelines for reporting observational studies. Lancet. 2007;370(9596):1453-1457.

17. Kumar BN, Grødvedt L, Meyer HE, Søgaard AJ, Heine Strand B. The Oslo Immigrant Health Profile. Rapport 2008:7. Oslo: Nasjonalt folkehelseinstitutt, 2008. Available from: http://www.fhi.no/ dav/920ab22ad5.pdf. Accessed July 10, 2012.

18. Gadd M, Sundquist J, Johansson SE, Wändell P. Do immigrants have an increased prevalence of unhealthy behaviours and risk factors for coronary heart disease? Eur J Cardiovasc Prev Rehabil. 2005;12(6):535-541.

19. Dawson AJ, Sundquist J, Johansson SE. The influence of ethnicity and length of time since immigration on physical activity. Ethn Health. 2005;10(4):293-309.

20. Pudaric S, Sundquist J, Johansson SE. Major risk factors for cardiovascular disease in elderly migrants in Sweden. Ethn Health. 2000;5(2):137-150.

21. Tomson Y, Aberg H. Risk factors for cardiovascular disease - a comparison between Swedes and immigrants. Scand J Prim Health Care. 1994;12(3):147-154.

22. Cleland SJ, Naveed S. Impact of ethnicity on metabolic disturbance, vascular dysfunction and atherothrombotic cardiovascular disease. Diabetes Obes Metab. 2005;7(5):463-470.

23. Tan CE, Tai ES, Tan CS, et al. APOE polymorphism and lipid profile in three ethnic groups in the Singapore population. Atherosclerosis. 2003;170(2):253-260.

24. King KM, Khan NA, Quan H. Ethnic variation in acute myocardial infarction presentation and access to care. Am J Cardiol. 2009; 103(10):1368-1373.

25. Vaccarino V, Rathore SS, Wenger NK, et al. Sex and racial differences in the management of acute myocardial infarction, 1994 through 2002. N Engl Med. 2005;353(7):671-682.

26. Echols MR, Mahaffey KW, Banerjee A, et al. Racial differences among high-risk patients presenting with non-ST-segment elevation acute coronary syndromes (results from the SYNERGY trial). Am J Cardiol. 2007;99(3):315-321.

27. Venkat A, Hoekstra J, Lindsell C, et al. The impact of race on the acute management of chest pain. Acad Emerg Med. 2003;10(11): 1199-1208.

28. Gregory PM, Rhoads GG, Wilson AC, O’Dowd KJ, Kostis JB. Impact of availability of hospital-based invasive cardiac services on racial differences in the use of these services. Am Heart J. 1999;138(3 Pt 1): 507-517.

29. Cram P, Bayman L, Popescu I, Vaughan-Sarrazin MS. Racial disparities in revascularization rates among patients with similar insurance coverage. J Natl Med Assoc. 2009;101(11):1132-1139. 


\section{Publish your work in this journal}

Vascular Health and Risk Management is an international, peerreviewed journal of therapeutics and risk management, focusing on concise rapid reporting of clinical studies on the processes involved in the maintenance of vascular health; the monitoring, prevention and treatment of vascular disease and its sequelae; and the involvement of metabolic disorders, particularly diabetes. This journal is indexed on PubMed Central and MedLine. The manuscript management system is completely online and includes a very quick and fair peer-review system, which is all easy to use. Visit http://www.dovepress.com/ testimonials.php to read real quotes from published authors.

Submit your manuscript here: http://www.dovepress.com/vascular-health-and-risk-management-journal 